\title{
LONG TERM EFFECTS OF CHEMOTHERAPY ON SALIVARY SECRETION IN CHILDREN CANCER SURVIVORS
}

\author{
O. Németh ${ }^{1}$, I. Pinke ${ }^{2}$, P. Kivovics ${ }^{3}$, M. Garami ${ }^{4}$ \\ ${ }^{1}$ 2nd Department of Pediatrics, Department of Prosthodontics, Semmelweis University, Budapest, \\ ${ }^{2}$ Department of Orthodontics and Pediatric Dentistry, University of Szeged, Szeged, ${ }^{3}$ Department of \\ Prosthodontics, ${ }^{4}$ 2nd Department of Pediatrics, Semmelweis University, Budapest, Hungary
}

Background: The aim of this prospective study is to investigate the long-term effects of chemotherapy on the oral health of children with a primary focus on salivary gland function.

Methods: Thirty-eight children (age [mean]: $12.3 \pm 0,58$ years) that underwent chemotherapy between 1 month and 7 years of age formed the study group. Forty, age- and gender-matched healthy children with similar socioeconomic background served as controls. Subjects' cariological status (DMF-T; number of decayed, missing and filled permanent teeth) was recorded according to the WHO criteria. Unstimulated and stimulated whole saliva flow rates were determined using method described by Shreebny. Palatal saliva flow rate was assessed with the Periotron method and buffer capacity was also studied.

Results: Stimulated whole saliva flow rate was significantly lower while palatal saliva flow rate was significantly higher in the study group compared to the controls $\left(\left(0,849 \pm 0,47 \mathrm{vs} .1,132 \pm 0,48 \mathrm{ml} \mathrm{min}^{-1}\right.\right.$ and $1,64 \pm 2,41$ vs. $0,456 \pm 0,32$ mikroL $\min ^{-1} \mathrm{~cm}^{-2}$, respectively; $\left.\mathrm{p}<0.05\right) .81,6 \%$ was high buffering capacity in the study group and $40 \%$ in the controls. No statistically significant differences were found between the genders.

Conclusion: These findings indicate that salivary gland function in children is affected even after years of completed cancer therapy. The clinical relevance of this finding is unclear and further studies need to be performed to answer this question. 